\title{
Assessing Sleep-Wake Pattern and Chronotype with the Korean Munich ChronoType for Shift-Workers in Shift Working Nurses
}

\author{
Su Jung Choi ${ }^{1,2}$, Sooyeon $\mathrm{Suh}^{3}$, Eun Yeon Joo $^{2}$ \\ ${ }^{1}$ Department of Nursing, Samsung Medical Center, Department of Clinical Nursing Science, Sungkyunkwan University School of Medicine, Seoul, \\ ${ }^{2}$ Department of Neurology, Brain-Nerve Center, Samsung Medical Center, Samsung Biomedical Research Institute (SBRI), \\ Sungkyunkwan University School of Medicine, Seoul, \\ ${ }^{3}$ Department of Psychology, Sungshin University, Seoul, Korea
}

\author{
한국어판 교대근무자용 뮌헨 일주기유형 설문지를 통해 분석한 \\ 교대근무 간호사의 수면-각성 양상과 일주기유형 \\ 최수정 ${ }^{1,2}$, 서수연 ${ }^{3}$, 주은연 ${ }^{2}$ \\ 삼성서울병원 간호부 · 성균관대학교 임상간호대학원, ${ }^{1}$ 성균관대학교 의과대학 신경과학교실 - 삼성서울병원 뇌신경센터 ${ }^{2}$, \\ 성신여자대학교 심리학과 ${ }^{3}$
}

\begin{abstract}
Received April 6, 2017
Revised June 7,2017

Accepted June 13, 2017
\end{abstract}

Address for correspondence

Eun Yeon Joo, MD

Department of Neurology,

Brain-Nerve Center,

Samsung Medical Center,

Samsung Biomedical Research

Institute (SBRI), Sungkyunkwan

University School of Medicine,

81 Irwon-ro, Gangnam-gu, Seoul

06351, Korea

Tel: +82-2-3410-3599

Fax: $+82-2-3410-0052$

E-mail: eunyeon.joo@gmail.com
Objectives: To investigate sleep-wake patterns and chronotype in rapidly rotating shift nurses (SRN). Methods: We translated and back-translated the Korean Munich ChronoType for Shift-Workers (K-MC$\mathrm{TQ}^{\text {shift }}$ ) with original authors' permission. In this study, 353 full-time, SRN (age 28.7 \pm 3.95 years 341 females, mean shift-working duration=5 years 9 months) at one university hospital completed the K-MCTQ ${ }^{\text {shift }}$ and the Morningness-Eveningness Questionnaire (MEQ). Time in bed, sleep duration, and mid-sleep time (sleep onset time+1/2 sleep duration) were evaluated on work days and free days. Social jet lag was computed for each shift. Chronotype was assessed based on the mid-sleep time on free days corrected for sleep debt accumulated over the workweek (MSF $F_{S C}$ ). Results: Sleep duration on workdays were 5.2 hours (day shift, D), 7.7 hours (evening shift, E), and 5.7 hours (night shift, N), respectively. Alarm clock usage on workdays was the highest in day-shifts $(92.4 \%)$. The chronotype of 166 SRN who did not use alarm on free days was 6:09 h. Social jet lag was the longest in day-shifts (3.3 hours), and the shortest in evening-shifts (0.3 hour). Mid-sleep after the evening-shift $\left(\mathrm{MSW}^{\mathrm{E}}, \mathrm{MSF}^{\mathrm{E}}, \mathrm{MSF}^{\mathrm{E}}{ }_{\mathrm{SC}}\right)$ showed significant correlations with MEQ scores. Conclusions: The Korean MCTQ ${ }^{\text {shift }}$ provides actual sleep-wake patterns per shift schedule and chronotype in shift workers. We suggest that the sleep-corrected version of mid-sleep on free days after evening shifts $\left(\mathrm{MSF}_{\mathrm{SC}}^{\mathrm{E}}\right)$ is suitable for assessing chronotype in shift workers.

J Sleep Med 2017;14(1):23-35

Key Words: Shift work, Chronotype, Sleep-wake pattern, Munich ChronoType for Shift-Workers.
서 론

문명과 산업이 발달하면서 24시간 가동되는 직장이 많아 지고 교대근무자의 수도 증가하고 있다. 교대근무로 인한 불 규칙한 수면-각성은 생체 내부의 일정한 주기성을 유지하 는 일주기 리듬과의 불일치를 초래해 수면장애의 원인이 되

This is an Open Access article distributed under the terms of the Creative Commons Attribution Non-Commercial License (http://creativecommons.org/licenses/by-nc/4.0) which permits unrestricted non-commercial use, distribution, and reproduction in any medium, provided the original work is properly cited.
며, ${ }^{1}$ 고혈압, 고지혈증, 인슐린저항성 증가, 암 등의 질환 발 생률도 증가시켜 건강에도 부정적인 영향을 미친다. 2,3

수면-각성 양상은 개인의 일주기유형(chronotype)에 따라 차이를 보인다. 일주기유형은 개인의 수면-각성 선호도로 아 침형, 중간형, 저녁형으로 분류하며, 저녁형 성향을 가질수록 더 늦게 잠을 자는 성향을 보인다. ${ }^{4}$ 일반적으로 저녁형은 아 침형에 비해서 주중 수면시간이 적어 주말에 수면의 요구도 가 많고, 수면-각성 시간이 불규칙하고 카페인 섭취량이 더 많다. ${ }^{5}$ 불면증 환자를 대상으로 한 연구에서는 저녁형 일주 
기유형을 가진 환자가 아침형이나 중간형보다 잠을 더 많이 자더라도 불면증상이 더 심하다는 보고도 있다. ${ }^{6}$ 교대근무자 의 경우에도 일주기유형에 따라 교대근무 적응이나 수면장 애 호소에 차이를 보인다. 아침형의 경우 밤 근무시 수면시간 이 짧고 사회적 시차가 크며 수면장애 빈도가 높아진다는 보 고가 있다. ${ }^{7}$

일주기유형을 평가하는 방법은 생리적 지표 측정방법과 자가보고 설문지 방법으로 나뉜다. 생리적 지표인 멜라토닌 이 가장 정확하다고 알려져 있지만, 엄격하게 신체활동과 조 명이 통제된 상태에서 모니터링을 하면서 측정해야 하므로 비용과 시간상 어려움이 많다. ${ }^{8}$ 일주기유형을 측정하는 자기 보고식 질문지 중 가장 많이 사용되는 아침형-저녁형 설문지 (Morningness-Eveningness Questionnaire, MEQ)는 개인의 수면-활동 선호도를 묻는 도구로 많은 연구들에서 활용되고 있지만 실제 수면시각에 대해서는 평가하지 않는 한계점을 가지고 있으며, 근무일과 휴일의 수면시간이 다름을 고려하 지 않아 일상적인 수면시간을 반영하는 일주기유형은 제공 하지 못한다는 단점이 있다.

MEQ에 비해 뮌헨 일주기유형 설문지(Munich ChronoType Questionnaire, MCTQ)는 주중과 주말의 수면-각성 양 상을 따로 측정한다. 따라서, 가장 깊게 잠이 드는 중간수면 (mid-sleep, MS)을 계산할 수 있고, 주중 출근 등으로 인해 부족한 수면을 주말에 보충하여 주중과 주말에 수면시간이 달라지는 사회적 시차(social jet lag)를 보정한 중간수면을 추출할 수 있다. ${ }^{9}$ 중간수면은 개인의 멜라토닌 최고치와 높 은 상관성을 보이는 것으로 보고되었다. ${ }^{10}$ 최초 독일어로 개 발된 MCTQ는 현재 영어, 프랑스어, 스페인어, 일본어, 네덜 란드어 등으로 번역되어 사용 중이며(https://www.thewep. org/chronotype-study), ${ }^{10,11}$ 국내에서도 한국어판으로 번역 되어 타당도 조사 후 논문 작업 중이다. 교대근무자용 $\mathrm{MCTQ}$ $\left(\mathrm{MCTQ}^{\text {shift }}\right)$ 는 $\mathrm{MCTQ}$ 설문지를 주간, 오후, 야간 근무별로 근무일과 휴일을 나눠서 측정하고 있으며, 근무일과 휴일 간 시차를 교정한 중간수면을 계산할 수 있다. ${ }^{12}$

이에 본 연구에서는 대표적인 교대근무자인 병원에서 근 무하는 빠른 3교대 간호사를 대상으로 $\mathrm{MCTQ}^{\text {shift }}$ 설문지를 한국어로 번역하여 1) 근무유형에 따른 수면-각성 양상과 일 주기유형을 조사하고, 2) 가장 많이 이용되는 일주기유형 평 가도구인 아침형-저녁형 설문지(MEQ)와 비교 분석을 하고 자 한다.

\section{방 법}

\section{연구 설계}

본 연구는 Roenneberg 등이 개발한 뮌헨 일주기유형 설문
지(MCTQ)에 근거하여 Juda 등이 교대근무자를 위해 사용 한 교대근무자용 뮌헨 일주기유형 설문지 $\left(\mathrm{MCTQ}^{\text {shift }}\right)$ 를 한 국어로 번역 및 역번역을 하였으며, ${ }^{2,13}$ 교대근무자의 수면각성 양상과 일주기유형을 분석한 서술적 조사연구이다. 그 외 기존 일주기유형을 평가하는 $\mathrm{MEQ}$ 도구와의 연관성을 분 석하여 대체 가능성을 평가하고자 하였다. 도구의 특성이 수 면-각성 시간을 측정하는 것이라 추가적인 신뢰도를 조사 할 수 없음을 원저자에게 확인하였다.

\section{연구 대상자}

본 연구의 대상자는 서울 소재 2,000병상 이상인 1 개 상급 종합병원에서 1년 이상 야간근무가 포함된 빠른 3교대근무 (주간근무 7:00 15:00, 오후근무 14:30 22:00, 야간근무 21:30 7:00)를 하고 있는 간호사 중, 연구 목적을 설명하고 연구에 참여할 것을 서면으로 동의한 간호사를 대상으로 하 였다. 총 416명에게 설문지가 배포 후 수거되었다. 수거된 설문 중 교대근무 경력 1년 미만 6 명, 야간 고정근무자 2명, 주간근무 시작시간이 10 시로 통상 근무와 다른 2 명, 설문응 답 누락자 53명을 제외한 총 353명의 자료가 1차 분석되었 다. 그러나 근무일과 휴일 간 시차를 교정한 중간수면을 측정 하기 위해서는 휴일에는 알람을 사용하지 않아야 하고, 2주 간의 근무일정이 파악되어 평균 수면시간을 계산해야 했다. 전체 353명 중 126 명(35.7\%)이 주간, 오후, 또는 야간근무 후 휴일에 알람을 사용하였고, 나머지 대상자 중 61명(17.3\%) 은 2주간 근무일정이 없어 평균 수면시간을 측정할 수 없어 제외되었다. 최종적으로 166 명의 대상자에서 교정한 중간수 면을 측정할 수 있었다.

\section{자료 수집 방법과 윤리적 고려}

자료 수집은 연구 대상자가 근무하고 있는 $\mathrm{S}$ 병원의 기관생 명윤리위원회의 승인(IRB No: 2015-05-127)을 받은 후 진 행되었으며, 자료 수집은 2015년 11월 4일부터 21일까지 진 행되었다. 설문지는 연구자가 직접 배부하였으며, 연구에 참 여하기로 자발적으로 동의한 대상자들에게 설문지와는 별 도로 작성된 서면 동의서를 배부하고 연구 참여와 자료 사용 에 대하여 동의서에 서명한 후 개별적으로 설문내용을 작성 하도록 하였다. 수집된 자료는 연구 목적 이외의 다른 목적으 로는 사용하지 않을 것을 명시하였고, 연구 참여과정 중 원 치 않으면 언제든 참여를 취소할 수 있고, 비밀 보장과 무기 명으로 처리됨을 기술하였다. 설문지 작성 후 설문지와 동의 서를 각각 별도로 회수하여 잠금 장치가 있는 장소에 보관하 였으며, 익명으로 코딩화하여 비밀보호가 유지되도록 하였다. 
연구 도구

교대근무자용 뮌헨 일주기유형 설문지 $\left(\mathrm{MCTQ}^{\text {shift }}\right)$

$\mathrm{MCTQ}^{\text {shift }}$ 는 교대근무자용 수면-각성 양상을 사정하기 위 해 개발된 도구로, MCTQ 도구를 근간으로 하여 개발되었 다. ${ }^{12,13} \mathrm{MCTQ}$ 는 주중과 주말의 수면-각성 양상을 조사하나, $\mathrm{MCTQ}^{\text {shift }}$ 는 주간근무(morning, M), 오후근무(evening, E), 야간근무(night, N)에 따른 근무일(work days, W)과 휴일 (free days, F)을 별도로 하여 총 6가지의 수면-각성 양상을 조사한다. 한 세트에 포함된 질문은 질문의 이해를 돕기 위 해 그림과 함께 구성되고, 1) 잠자리에 들어간 시각(Fig. 1), 2) 잠자리에 들어갔지만 깨서 다른 일(예: 핸드폰, 책 읽기 등)을 한다면, 실제 잠을 청하려고 불을 끄거나 눈을 감은 시 각(lights out), 3) 잠을 청한 후 잠드는 데 걸리는 시간(sleep latency), 4) 잠에서 깬 시각(wake time)과 알람 사용 유무, 5) 잠자리에서 나온 시각(time out of bed), 6) 낮잠 유무와 낮 잠시간, 7) 수면시간을 자유롭게 선택하지 못하는지 여부와 사유를 작성하도록 되어 있다. 독일어로 작성된 원본 $\mathrm{MC}-$ $\mathrm{TQ}^{\text {shift }}$ 는 현재 영어, 네덜란드어로 번역되어 사용 중이다. ${ }^{14}$

설문응답을 통해서 수면 시작시각(sleep onset, $\mathrm{SO}=$ time of preparing to fall asleep+sleep latency)과 수면이 끝나는 시각(sleep end, $\mathrm{SE}=$ time of awakening)을 확보할 수 있다. $\mathrm{SO}$ 와 $\mathrm{SD}$ 를 통해 수면기간(sleep duration, $\mathrm{SD}$ )과 중간수면 (MS)을 계산한다:
$\mathrm{SD}=\mathrm{SE}-\mathrm{SO}$

\section{$\mathrm{MS}=\mathrm{SO}+\mathrm{SD} / 2$}

위 변수들은 근무일과 휴일에 별도로 계산한다 $\left[\mathrm{SD}_{\mathrm{W}} \&\right.$ $\mathrm{SD}_{\mathrm{F}}$; mid-sleep time on workdays(MSW) \& mid-sleep time on free days(MSF)]. 상근자를 대상으로 하는 MCTQ 에서는 근무일(평일)과 휴일만을 구분하면 되나, $\mathrm{MCTQ}^{\text {shift }}$ 는 각기 다른 근무조에 따른 수면 정보를 얻는다[예: 근무일 중간수면 $\left(\mathrm{MSW}^{\mathrm{M} / \mathrm{E} / \mathrm{N}}\right)$, 휴일 중간수면( $\left.\left(\mathrm{MSF}^{\mathrm{M} / \mathrm{E} / \mathrm{N}}\right)\right]$. 마찬가지로 수면시간도 근무조에 따라 근무일과 휴일에 모두 계산한다 $\left(\mathrm{SD}_{\mathrm{W}}^{\mathrm{M} / \mathrm{E} / \mathrm{N}}, \mathrm{SD}_{\mathrm{F}}{ }^{\mathrm{M} / \mathrm{E} / \mathrm{N}}\right)$. 평균 수면기간(ØSD)은 조사기간 동안 의 근무일과 휴일의 평균 수면기간으로, 교대근무자의 근무 스케줄에 기반해서 계산한다. ${ }^{12}$ 따라서 설문에 참여한 대상 자의 근무 스케줄을 보고 각 근무조의 근무일과 휴일 개수를 확인한 상태에서 $\varnothing \mathrm{SD}$ 는 아래와 같은 방법으로 산출한다:

$$
\varnothing \mathrm{SD}=\frac{\left(\mathrm{SD}_{\mathrm{W}}^{\mathrm{M} / E / \mathrm{N}} \times \mathrm{n}_{\mathrm{W}}^{\mathrm{M} / \mathrm{E} / \mathrm{N}}+\mathrm{SD}_{\mathrm{F}}^{\mathrm{M} / E / N} \times \mathrm{n}_{\mathrm{F}}^{\mathrm{M} / E / N}\right)}{\left(\mathrm{n}_{\mathrm{W}}^{\mathrm{M} / E / \mathbb{N}}+\mathrm{n}_{\mathrm{F}}^{\mathrm{M} / E / \mathbb{N}}\right)}
$$

만약 근무일의 수면시간과 휴일의 수면시간이 같으면 휴 일 중간수면이 일주기유형이 될 수 있으나, 휴일 수면이 근무 일보다 더 길다면 근무일에 부족한 수면시간을 보충하는 것 이기 때문에 평소 수면부족분을 보정한 교정된 중간수면으 로 계산한다. 상근자의 경우에는 휴일 중간수면(MSF)에서 평일과 휴일 간 수면시간의 차이를 보정한 교정된 휴일 중 간수면(mid-sleep time on free days corrected for sleep

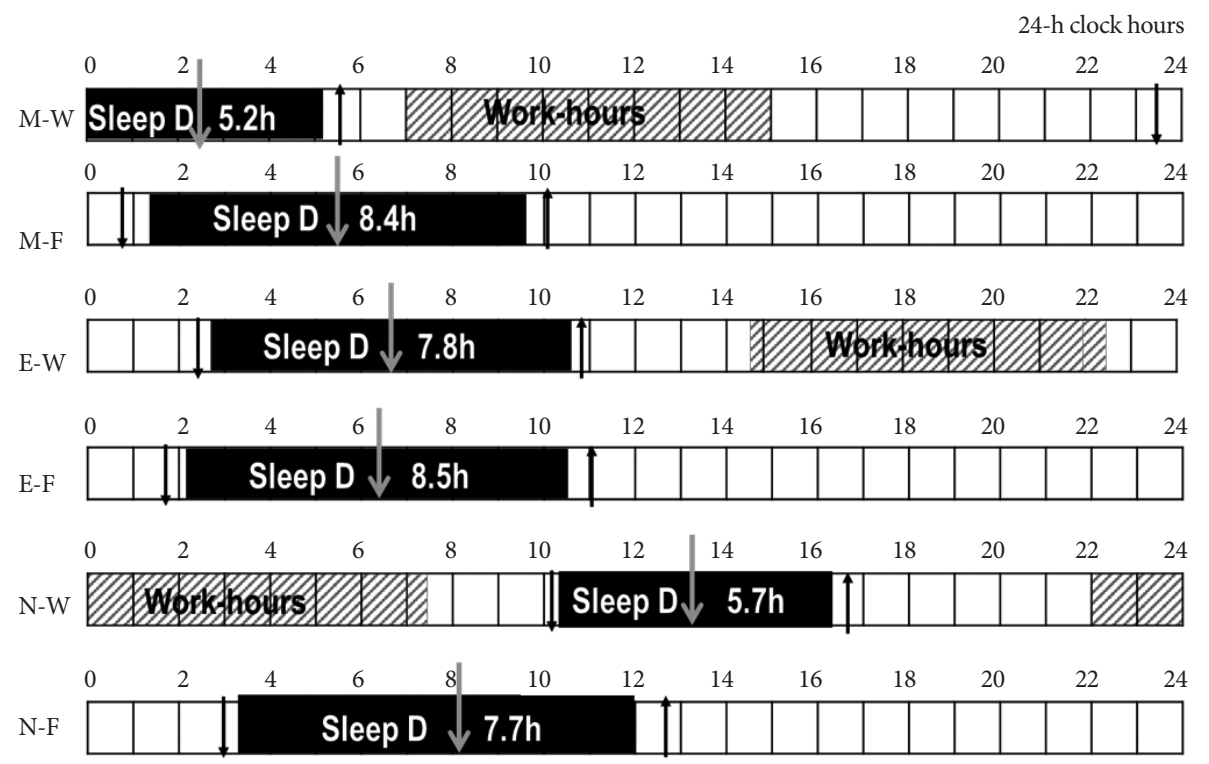

Figure 1. Sleep duration and mid-sleep separately for work and free days, in each shift of 3-shift nurses ( $n=353)$. The striped box indicates work-hours; the black box is sleep duration. Downside black arrows $(\downarrow)$ are the time of preparing to fall asleep; the upside black arrows $(\uparrow)$ are the time to get up; the gray arrows are mid-sleep. M: morning shift, E: evening shift, N: night shift, W: workdays, F: free days, sleep D: sleep duration. 
debt accumulated over the workweek, MSFsc)으로 산출하 나, 교대근무자의 경우에는 오후근무 후 이틀 연속 쉬는 날 중 이틀째 휴일에서 근무일과 휴일 간 수면시간의 차이를 보정한 교정된 중간수면 $\left(\mathrm{MSF}_{\mathrm{SC}}^{\mathrm{E}}\right)$ 을 산출하고, 이것을 시간 변수로 계산한 일주기유형으로 한다:

$\mathrm{MSF}_{\mathrm{SC}}^{\mathrm{E}}=\mathrm{MSF}^{\mathrm{E}}-\left(\mathrm{SD}_{\mathrm{F}}{ }^{\mathrm{E}}-\varnothing \mathrm{SD}\right) / 2$

상근자의 경우와 마찬가지로 교대근무자의 오후근무(E) 후 휴일의 수면기간 $\left(\mathrm{SD}_{\mathrm{F}}^{\mathrm{E}}\right)$ 이 근무일의 수면기간 $\left(\mathrm{SD}_{\mathrm{w}}^{\mathrm{E}}\right)$ 보다 길지 않다면, 일주기유형은 다음과 같다:

$\mathrm{MSF}_{\mathrm{SC}}^{\mathrm{E}}=\mathrm{MSF}^{\mathrm{E}}$

\section{아침형-저녁형 설문지}

아침형-저녁형 설문지(MEQ)는 Horne와 Ostberg가 개발 하고 Park 등이 번안한 한국어판 아침-저녁형 질문지(MEQ) 로 측정한다. ${ }^{415} \mathrm{MEQ}$ 는 총 19 문항으로 5항목은 5지선다형, 나머지 14문항은 4지선다형으로 구성된 16 86점의 자가보 고형 설문도구이다. 설문문항의 점수의 합이 16 41점까지는 아침형, 42 58점은 중간형, 59 86점은 저녁형으로 분류한 다. ${ }^{15}$ 도구의 신뢰도는 Horne와 Ostberg의 연구에서는 Cronbach's alpha 0.82였고, 본 연구의 신뢰도는 Chronbach's alpha 0.72 였다. ${ }^{4}$

\section{도구 번역 절차}

도구 번역 및 적용과정은 세계보건기구의 가이드라인에 따라 순번역(forward translation), ${ }^{16}$ 전문가 패널, 역번역 (back translation), 사전 조사 및 최종 완성 순서로 진행하였 다. 한국어판 $\mathrm{MCTQ}$ shifte를 진행하기 위해서 원저자로부터 도 구 사용 허가와 영문 설문도구를 받았다. 일차 번역에서는 도구 용어에 익숙한 이중 언어 사용자가 한국어로 번역하였 다. 원문과 번역본 사이의 불일치 및 문화적 차이로 인한 표 현 등을 비교하기 위해, 전문가 패널(수면의학 전문의, 이중 언어가 가능한 심리학과 교수, 간호학과 교수)이 함께 모여 번역된 설문지를 원본과 대조하여 문맥상 의미가 잘 전달 되는지 의견이 일치할 때까지 수정하였다. 또한 원본에서 사 용된 그림은 원저자에게 허가를 받아 문화적 특성을 고려하 여 수정하였다.

번역 및 역번역을 통해 완성된 설문지는 의미 타당도(semantic validity)를 확보하기 위해서 경기도 소재 1개 2차 종 합병원에서 3 교대근무를 하고 있는 간호사 77 명 (평균 나이

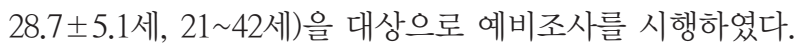
본 연구 저자들이 예비조사에서 수거된 설문의 응답이 원도 구의 의도를 반영하고 있는지 모두 검토하였다. 원도구의 의 도와 일치하지 않는 내용에 대해 단어와 문장을 수정하여
번역, 역번역 과정을 다시 반복하였고, 이후 최종적으로 한 국어판을 완성하였다.

예비조사에서 대상자인 교대근무 간호사들은 근무일과 휴일의 수면시간이 어떤 상태의 수면에 대한 것인지 의미파 악이 어렵다고 보고한 경우가 많았다. 이에 근무일과 휴일의 개념을 명확하게 하기 위해서 원도구에 없는 근무 중 수면 과 휴일 중 수면에 대한 개념을 그림으로 추가하였다(예: '주 간근무 중 수면'은 이틀 연속 주간근무를 하고 있는 중간의 수면을 의미하도록 '주간근무-수면-주간근무'를 표시, '주간 근무 후 수면'은 주간근무 후 이틀 연속으로 휴일이 있을 때 휴일과 휴일 사이의 수면을 의미하도록 '주간근무-휴일-수 면-휴일'로 표시). 두 번째로 잠자리에 들어가는 시간(Appendix, 설문지 그림 (1)과 실제 잠을 취하려고 하는 시간(Appendix, 설문지 그림 (3)과의 혼동이 심했다. 전체 대상자의 $42.9 \%$ (33명)만이 설문지를 올바르게 작성하였는데, 특히 위 질문 에 대한 혼동이 많았다. 이러한 혼동은 일본어판 MCTQ 타 당도 조사에서도 보고되었으며, ${ }^{10}$ 원저자를 통해서도 메일로 확인하였다. 이에 원도구에 있는 '실제로 잠들기 위해 준비 하는 시간' 문항에 ‘불을 끄고 눈을 감는다’라는 예시문을 추 가하여 한국어판 도구를 확정하였고, 원저자에게도 변경 허 락을 구하였다.

\section{자료분석 방법}

수집된 자료는 유의수준 0.05 로 하여 윈도우용 SPSS 20.0 (IBM Inc., Chicago, IL, USA)를 이용하여 다음과 같이 분 석하였다. 대상자의 일반적 특성은 빈도와 백분율, 평균과 표준편차를 이용하였다. 연속변수의 경우 $\mathrm{MEQ}$ 와 $\mathrm{MCTQ}^{\text {shift }}$ 변수들의 정규성 여부를 확인 후 Student t-test, Mann-Whitney U test, 또는 Friedman test를 시행하였다. 범주형 변수의 경우 chi-square test와 Fisher's exact test를 시행하였다. MEQ 와 $\mathrm{MCTQ}^{\text {shift }}$ 변수들 간의 상관분석은 Spearman's correlation(rho)을 이용하여 분석하였다.

\section{결 과}

\section{일반적 특성}

대상자의 일반적 특성은 Table 1과 같다. 전체 353 명의 평 균 연령은 28.7세(22 43세)이고, 72.2\%가 미혼이었다. 교대 근무로 근무한 간호사 경력은 평균 5년 9개월이었다. 주당 평균 카페인 섭취량은 커피 8.3잔이었고, 수면제를 복용한 경우는 11 명으로 전체의 $3.1 \%$ 였다. $\mathrm{MEQ}$ 로 측정한 점수로 구분한 일주기유형은, 중간형이 $57.5 \%$ 로 가장 많았고, 저녁 형이 $37.4 \%$, 아침형이 $4.2 \%$ 순서였다. 휴일 중 알람을 사용 
하거나 근무일정이 확인되지 않아 중간수면을 보정할 수 없 어 제외된 군과 최종 분석에 사용된 군 간의 일반적 특성은 차이가 없었다.

\section{근무조에 따른 근무일과 휴일의 수면 양상}

전체 353 명 대상자 각각의 근무조에 따른 근무일과 휴일 별 수면-각성 양상, 수면기간(sleep duration), 중간수면(midsleep)은 Table 2와 Fig. 1에 제시하였다. 근무일의 총 침상시 간(time in bed)은 근무유형에 따라 평균 6.6(M), 9.1(E), $6.8(\mathrm{~N})$ 시간이었고, 근무일 수면기간은 각각 $\mathrm{SD}_{\mathrm{w}}^{\mathrm{M}}: \mathrm{SD}_{\mathrm{w}}^{\mathrm{E}}$ : $\mathrm{SD}_{\mathrm{W}}{ }^{\mathrm{N}}=5.2: 7.8: 5.7$ 시간으로 오후근무 동안의 수면시간이 가 장 길었다. 기상 알람을 사용하는 빈도는 주간근무 $(\mathrm{M})$ 동안 가장 높았다(92.4\%). 반면 휴일의 경우 근무조에 따른 총 침 상시간은 유사하였고, 수면기간은 야간 근무조에서 더 짧았 다. 중간수면의 경우 오후근무(E)에서는 근무일과 휴일이 거의 유사하나, 주간과 야간근무에서는 차이를 보였다. 전체 대상자 중 휴일에 알람을 사용한 적이 있는 경우는 126 명 (35.7\%)이며, 주간근무보다 오후나 야간근무 후 휴일에 알람 사용 빈도가 더 높았다.

알람을 사용하지 않아서 일주기유형인 $\mathrm{MSF}_{\mathrm{SC}}^{\mathrm{E}}$ 를 계산할 수 있었던 166 명의 수면-각성 양상, 수면기간, 중간수면은
Table 3과 같다. 근무일 중간수면(MSW)은 근무조에 따라 유의한 차이를 보였고(Friedman test, $\chi^{2}=653.377, p<0.001$ ), 휴일 중간수면(MSF)도 유의한 차이를 보였다 $\left(\chi^{2}=74.606, p<\right.$ $0.001)$. 오후근무일 중간수면 $\left(\mathrm{MSW}^{\mathrm{E}}\right)$ 시각은 $6.7 \pm 1.2 \mathrm{~h}$ (3.8 10.0), 오후 휴일 중간수면( $\left.\mathrm{MSF}^{\mathrm{E}}\right)$ 시각은 $6.5 \pm 1.9 \mathrm{~h}$ (2.0 14.5), 근무조에 따른 수면기간의 차이를 교정한 $\mathrm{MSF}^{\mathrm{E}} \mathrm{SC}$ 시각은 $6.2 \pm 2.1 \mathrm{~h}(0.7 \sim 13.5)$ 였다. 한편, 근무일 수면기간 $\left(\mathrm{SD}_{\mathrm{w}}\right)$ 은 근무조에 따라 유의한 차이를 보인 반면 $\left(\chi^{2}=160.243, p<\right.$ $0.001)$, 휴일 수면기간 $\left(\mathrm{SD}_{\mathrm{F}}\right)$ 은 근무조에 따른 차이가 없었다 $\left(\chi^{2}=2.749, p=0.253\right)$. 근무일 수면기간은 $\mathrm{SD}_{\mathrm{w}}^{\mathrm{M}}: \mathrm{SD}_{\mathrm{w}}^{\mathrm{E}}: \mathrm{SD}_{\mathrm{w}}{ }^{\mathrm{N}}=$ 5.2:8.0:5.5시간으로 주간근무 동안 가장 짧고 오후 근무 동 안 가장 길었던 반면, 휴일 수면기간은 $\mathrm{SD}_{\mathrm{F}}{ }^{\mathrm{M}}: \mathrm{SD}_{\mathrm{F}}^{\mathrm{E}}: \mathrm{SD}_{\mathrm{F}}{ }^{\mathrm{N}}=$ 8.5:8.3:7.7시간으로 주간근무 동안 더 길었다.

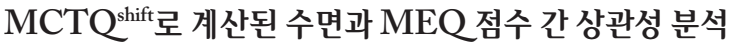

전체 353명의 $\mathrm{MEQ}$ 점수 평균은 44.3 \pm 7.6점(23 67)이었

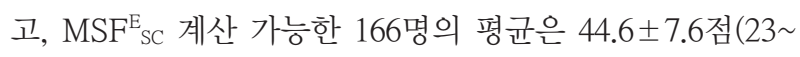
64)이었다. 각 근무조별 근무일과 휴일의 수면지표들과 $\mathrm{MEQ}$ 점수와의 상관계수는 Table 4와 같다. 전체 대상자와 $\mathrm{MSF}_{\mathrm{SC}}^{\mathrm{E}}$ 측정그룹 모두에서 수면시작(sleep start), 수면종료(sleep end)보다 중간수면 $\left(\mathrm{MSW}^{\mathrm{E}}, \mathrm{MSF}^{\mathrm{E}}, \mathrm{MSF}_{\mathrm{SC}}^{\mathrm{E}}\right)$ 이 $\mathrm{MEQ}$ 점수와

Table 1. General characteristics of all participants $(n=353)$

\begin{tabular}{|c|c|c|c|c|}
\hline Variables & $\begin{array}{c}\text { Total } \\
(\mathrm{n}=353)\end{array}$ & $\begin{array}{l}\text { No alarm in any free days } \\
\left(\mathrm{MSF}_{\mathrm{SC}}^{\mathrm{E}} \text { group }\right) \\
(\mathrm{n}=166)\end{array}$ & $\begin{array}{l}\text { Alarm use in any free days or } \\
\text { unknown work schedules } \\
(\mathrm{n}=187)\end{array}$ & $p$ \\
\hline Age, years & $28.65 \pm 3.95$ & $28.77 \pm 4.08$ & $28.88 \pm 4.01$ & 0.855 \\
\hline Female, n (\%) & $341(96.6)$ & $161(97.0)$ & $180(96.3)$ & 0.705 \\
\hline \multicolumn{5}{|l|}{ Marital status, n (\%) } \\
\hline Single & $255(72.2)$ & $123(74.1)$ & $132(70.6)$ & 0.102 \\
\hline Married & $95(26.9)$ & $40(24.1)$ & $55(29.4)$ & \\
\hline Divorced & $3(0.9)$ & $3(1.8)$ & $0(0)$ & \\
\hline Nursing career, months & $69.49 \pm 47.18$ & $69.61 \pm 48.82$ & $73.50 \pm 48.47$ & 0.866 \\
\hline $\mathrm{BMI}, \mathrm{kg} / \mathrm{m}^{2}$ & $20.33 \pm 2.34$ & $20.49 \pm 2.50$ & $20.12 \pm 2.08$ & 0.285 \\
\hline Alcohol consumption, drinks/week & $2.60 \pm 6.74$ & $3.18 \pm 3.94$ & $2.80 \pm 5.08$ & 0.431 \\
\hline Smoking, n (\%) & $4(1.1)$ & $2(1.2)$ & $2(1.1)$ & 1.000 \\
\hline Caffeine consumption, cups/week & $8.29 \pm 6.32$ & $6.59 \pm 7.43$ & $8.83 \pm 0.72$ & 0.621 \\
\hline Use of hypnotics, n (\%) & $11(3.1)$ & $6(3.6)$ & $5(2.7)$ & 0.419 \\
\hline \multicolumn{5}{|l|}{ Working hours } \\
\hline Day-shifts & $9.50 \pm 0.77$ & $9.52 \pm 0.72$ & $9.42 \pm 0.75$ & 0.695 \\
\hline Evening-shifts & $8.94 \pm 0.75$ & $8.93 \pm 0.73$ & $8.88 \pm 0.72$ & 0.931 \\
\hline Night-shifts & $9.89 \pm 0.81$ & $9.88 \pm 0.80$ & $9.82 \pm 0.81$ & 0.962 \\
\hline MEQ score & $44.26 \pm 7.64$ & $43.90 \pm 7.68$ & $44.29 \pm 7.35$ & 0.404 \\
\hline Morning type, n (\%) & $15(4.3)$ & $8(4.8)$ & $7(3.8)$ & 0.807 \\
\hline Intermediate type, $\mathrm{n}(\%)$ & $203(57.5)$ & $93(56.0)$ & $110(58.8)$ & \\
\hline Evening type, $\mathrm{n}(\%)$ & $135(38.2)$ & $65(39.2)$ & $70(37.4)$ & \\
\hline
\end{tabular}

BMI: body mass index, MEQ: Morningness-Eveningness Questionnaire 


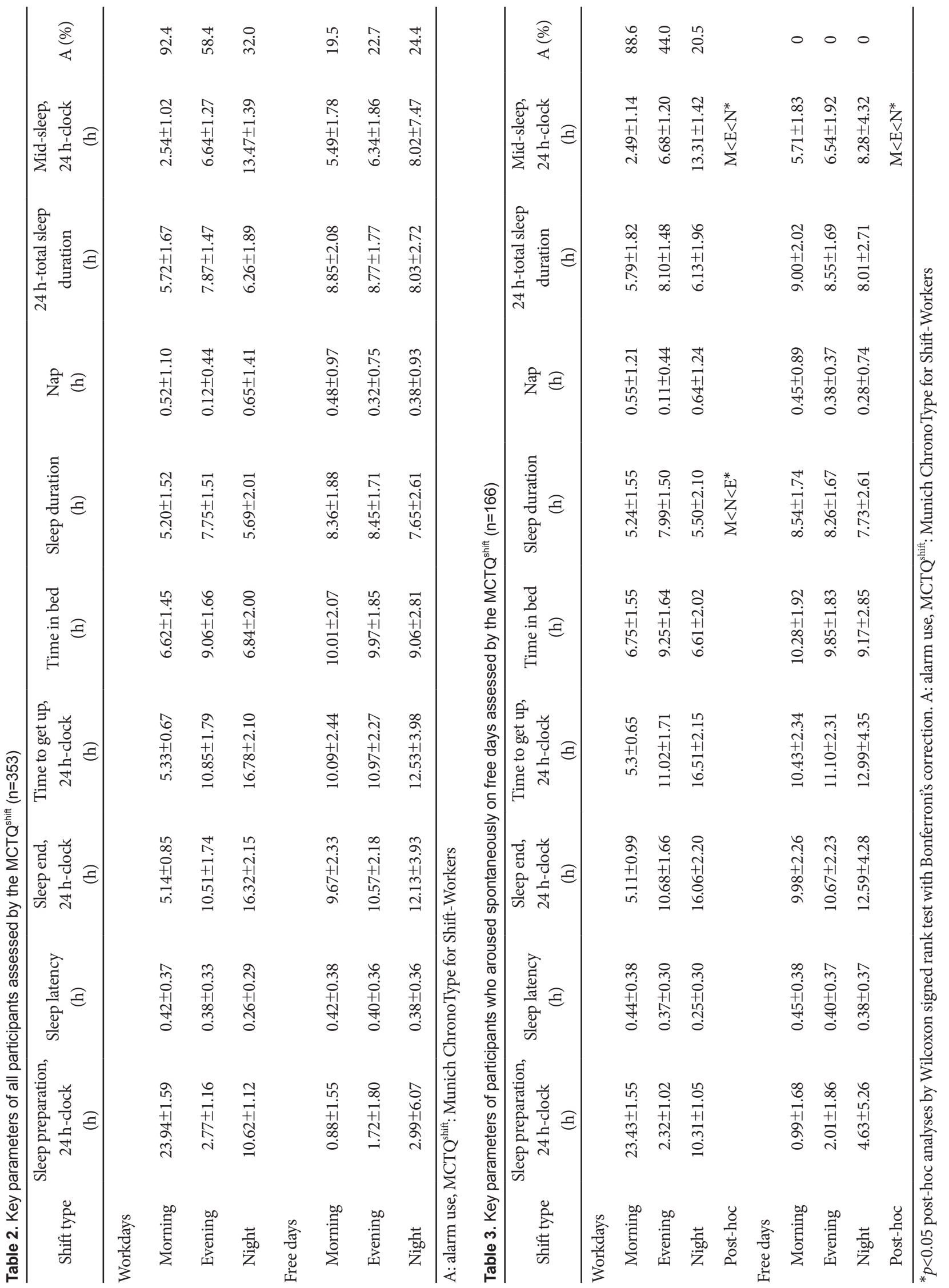


상관계수가 더 높았다 $(p<0.001)$, 그중 $\mathrm{MSW}^{\mathrm{E}}$ 의 상관계수가 가장 높았다. $\mathrm{MSF}_{\mathrm{SC}}^{\mathrm{E}}$ 계산군(n=166)에서 $\mathrm{MSW}^{\mathrm{E}}$ 는 $6 \mathrm{AM}$ 시 간대에 가장 많았고, $\mathrm{MSF}^{\mathrm{E}}$ 와 $\mathrm{MSF}_{\mathrm{SC}}^{\mathrm{E}}$ 는 $5 \mathrm{AM}$ 시간대에 가 장 많았다(Fig. 2A). MEQ 점수가 높은 아침형부터 역순으 로 나열한 빈도 분포도는 Fig. 2B와 같다.

\section{근무조별 근무일과 휴일 간 사회적 시차}

$\mathrm{MSF}_{\mathrm{SC}}$ 계산군에서 근무조별 근무일과 휴일 간 사회적 시차(social jet lag)는 오후근무에서 $0.3 \pm 1$.4시간으로 가장 적었고, 주간근무에서 $3.3 \pm 2.1$ 시간으로 가장 큰 것으로 나 타났다. $\mathrm{MSF}_{\mathrm{SC}}^{\mathrm{E}}$ 분포에 따른 근무조별 휴일간 사회적 시차 는 $\mathrm{MSF}_{\mathrm{SC}}^{\mathrm{E}}$ 가 7:00 h 이상인 경우 주간근무형태일 때 가장 격 차가 컸다(Fig. 3).

\section{고 찰}

교대근무자의 수면은 내제된 생체시계와 일치하지 않는
수면-각성 양상으로 인해 수면장애와 불건강 문제 외, 업무 중 피로로 인한 사고 발생 위험 증가, 수면 부적응으로 인한 이직률 증가 등 다양하고 심각한 문제들을 초래한다. 그럼에 도 불구하고, 국내에서는 교대근무에 따른 수면 실태에 대한 조사가 아직까지 미약하다. 본 연구는 교대근무자의 수면에 대한 관심과 연구 확대에 기여하고자 교대근무자의 수면각성 양상을 조사할 수 있는 $\mathrm{MCTQ}^{\text {shift }}$ 를 한국어로 번역하 고, 대표적인 교대근무자인 3교대 간호사에게 적용해서 교 대근무자의 수면 실태를 파악함으로써 교대근무자의 수면 을 이해하는 데 기여하고자 하였다. $\mathrm{MCTQ}^{\text {shift }}$ 의 장점은 근 무조별 근무일과 휴일의 수면-각성 양상을 모두 조사할 수 있고, 이를 통해 시간 기반 일주기유형(time-based chronotype)인 교정된 휴일의 중간수면( $\left.\mathrm{MSF}_{\mathrm{SC}}^{\mathrm{E}}\right)$ 을 계산할 수 있어, 개인의 수면-활동 선호도만으로 일주기유형을 점수화하는 $\mathrm{MEQ}$ 척도의 단점을 보완할 수 있다. ${ }^{17}$ 중간수면은 코티졸, 멜라토닌과 같은 생리적 지표나 actigraphy나 수면일지로 측정된 수면관련 지표와 높은 상관성을 보여서, 고가의 생리

Table 4. Correlation coefficients of the MCTQ ${ }^{\text {shift }}$ parameters with the MEQ scores (a higher MEQ score indicates "morningness")

\begin{tabular}{|c|c|c|c|c|c|c|c|c|}
\hline \multirow{2}{*}{ Group } & \multirow{2}{*}{ Shift type } & \multicolumn{3}{|c|}{ Workdays } & \multicolumn{3}{|c|}{ Free days } & \multirow{2}{*}{$\mathrm{MSF}_{\mathrm{SC}}^{\mathrm{E}}$} \\
\hline & & Sleep start & Mid-sleep & Sleep end & Sleep start & Mid-sleep & Sleep end & \\
\hline \multirow{3}{*}{$\begin{array}{l}\text { Total } \\
(\mathrm{n}=353)\end{array}$} & Morning shift & $-0.308^{* *}$ & $-0.138^{* *}$ & $-0.125^{*}$ & $-0.427^{* *}$ & $-0.492^{* *}$ & $-0.444^{* *}$ & \\
\hline & Evening shift & $-0.450^{* *}$ & $-0.540^{* *}$ & $-0.484^{* *}$ & $-0.395^{* *}$ & $-0.490^{* *}$ & $-0.496^{* *}$ & \\
\hline & Night shift & -0.049 & -0.097 & -0.102 & $-0.192^{* *}$ & $-0.193^{* *}$ & -0.100 & \\
\hline \multirow{3}{*}{$\begin{array}{l}\operatorname{MSF}_{\text {SC }}^{\mathrm{E}} \text { group } \\
(\mathrm{n}=166)\end{array}$} & Morning shift & $-0.227^{* *}$ & $-0.210^{* *}$ & -0.056 & $-0.363^{* *}$ & $-0.421^{* *}$ & $-0.403^{* *}$ & \\
\hline & Evening shift & $-0.459^{* *}$ & $-0.534^{* *}$ & $-0.455^{* *}$ & $-0.345^{* *}$ & $-0.462^{* *}$ & $-0.482^{* *}$ & $-0.405^{* *}$ \\
\hline & Night shift & -0.081 & -0.115 & -0.103 & -0.150 & $-0.223^{* *}$ & $-0.236^{* *}$ & \\
\hline
\end{tabular}

All correlations significant at the 0.05 level, two-tailed analyzed by Spearman correlation. ${ }^{*} p<0.05,{ }^{* *} p<0.01$. MEQ: morningness-eveningness questionnaire, $\mathrm{MSF}_{\mathrm{SC}}^{\mathrm{E}}$ : mid-sleep time on free days after evening shifts with sleep debt correction, MCTQ ${ }^{\text {shift: }}$ Munich ChronoType for Shift-Workers

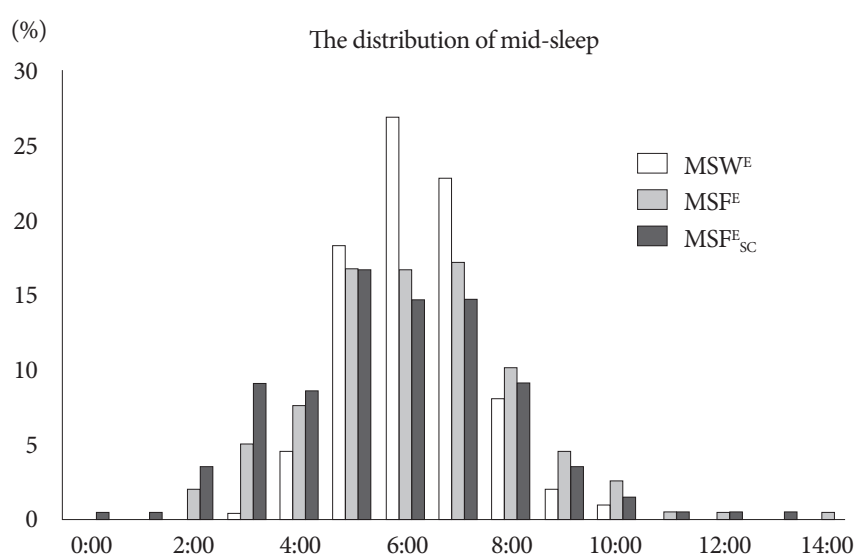

A

Figure 2. Distribution of mid-sleep on evening and Morningness-Eveningness Questionnaire (MEQ) scores. (A) The graphs show the distribution of mid-sleep times on work days after evening shifts $\left(\mathrm{MSW}^{\mathrm{E}}\right)$, free days after evening shifts (MSF$\left.)^{\mathrm{E}}\right)$, and free days after evening shifts with sleep debt correction $\left(\mathrm{MSF}_{\mathrm{SC}}\right.$ ) of 166 rapid rotating shift nurses. Data are binned in 1-hour intervals. (B) Distribution of MEQ scores of 166 rapid rotating shift nurses. Data are binned in 7-point intervals.

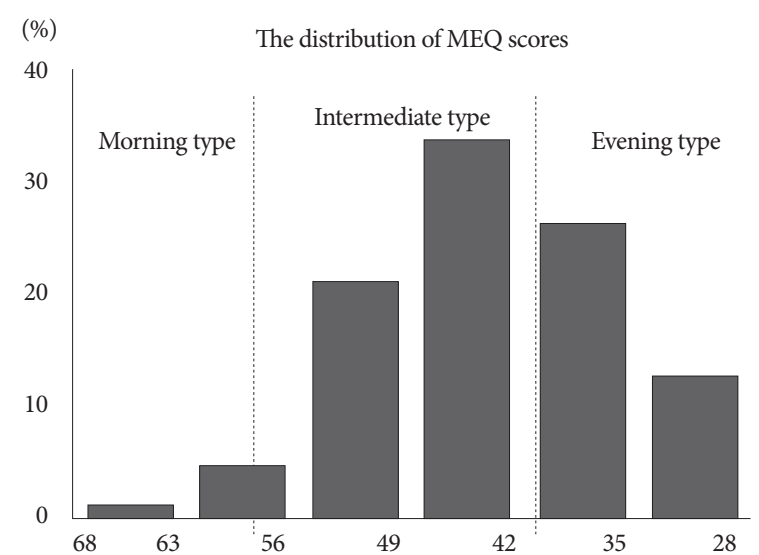

B 


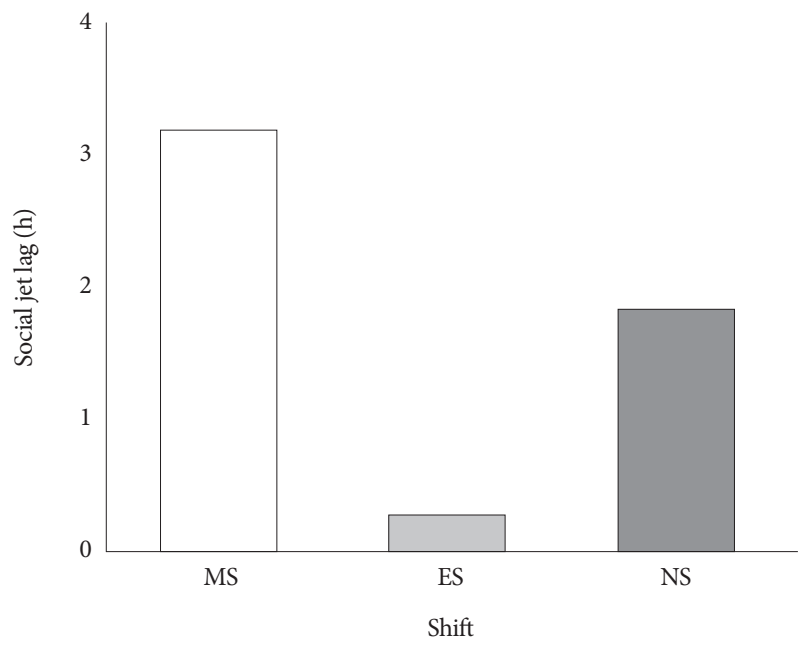

A

Figure 3. (A) Mean social jet lag across shifts $(n=166)$. (B) Mean chronotype modulation of social jet leg. Data are binned in 1-hour intervals. MS: morning shift, ES: evening shift, NS: night shift, $\mathrm{MSF}^{\mathrm{E}}{ }_{\mathrm{sc}}$ : sleep-corrected version of mid-sleep on free days after evening shifts.

적 지표 검사 없이도 일주기유형을 추정할 수 있다. ${ }^{12,18,19}$

본 연구에서 3교대근무 간호사들의 $\mathrm{MSF}_{\mathrm{SC}}$ 로 계산된 일 주기유형은 평균 6:09 AM으로 조사되었다. 아직 국내에서 상근자의 $\mathrm{MCTQ}$ 결과가 없어 비교할 수는 없지만, MCTQ 로 조사한 21 30세 독일인의 평일 MSW가 $3: 18 \mathrm{~h}$, 휴일 $\mathrm{MSF}$ 가 5:54 h이고, 일본에서 시행한 연구(평균 36.4세)의 $\mathrm{MSF}_{\mathrm{SC}}$ 는 4:40 h로, 보고된 연구들과 비교하면 본 교대근무 간호사의 일주기유형이 더 늦다. ${ }^{10,13}$ 독일에서 진행한 일반 인과 교대근무자 간의 $\mathrm{MCTQ}$ 와 $\mathrm{MCTQ}^{\text {shift }}$ 로 조사한 일주기 유형 분포도에서, 교대근무자의 일주기유형이 상근자보다 더 늦은 시간에 분포하는 것과 유사하다. ${ }^{12,20}$ 교대근무병 (shift work disorder)을 호소하는 야간근무자에 비해 증상 호소가 없는 야간근무자가 dim light of melatonin onset (DLMO) 시간이 더 늦었고, 24시간 멜라토닌 분비량이 더 많았다. ${ }^{21}$ 또한 $\mathrm{DLMO}$ 가 지연될수록 주관적 불면증 점수가 낮다고 한다. ${ }^{21}$ 본 연구의 교대근무자의 일주기유형이 지연 되는 이유는 불명확하지만, 앞서 언급한 외국의 선행연구 결 과로 추정해본다면, 교대근무 적응을 위해 본 피험자들이 일 주기유형을 늦춘 것으로 추정한다. 하지만, 언급한 선행연구 가 조도와 소음이 모두 통제되는 실험실에서 5명의 대상자 로 시행되었기 때문에, ${ }^{21}$ 교대근무자 전체로 일반화시키기에 는 제한이 있다. 따라서, 좀 더 많은 수의 교대근무자에서 생 리적 지표와 수면-각성 측정도구를 이용한 일주기유형 평 가 연구가 수행되어야 할 것이다.

교대근무 간호사들의 근무조에 따른 수면기간(sleep duration)은, 주간근무에서 근무일과 휴일 간 사회적 시차가 가 장 크고, 오후근무에서 가장 적었다. 이는 본 교대근무자의 일주기유형이 평균 6:09 h인데, 주간근무와 야간근무일 에

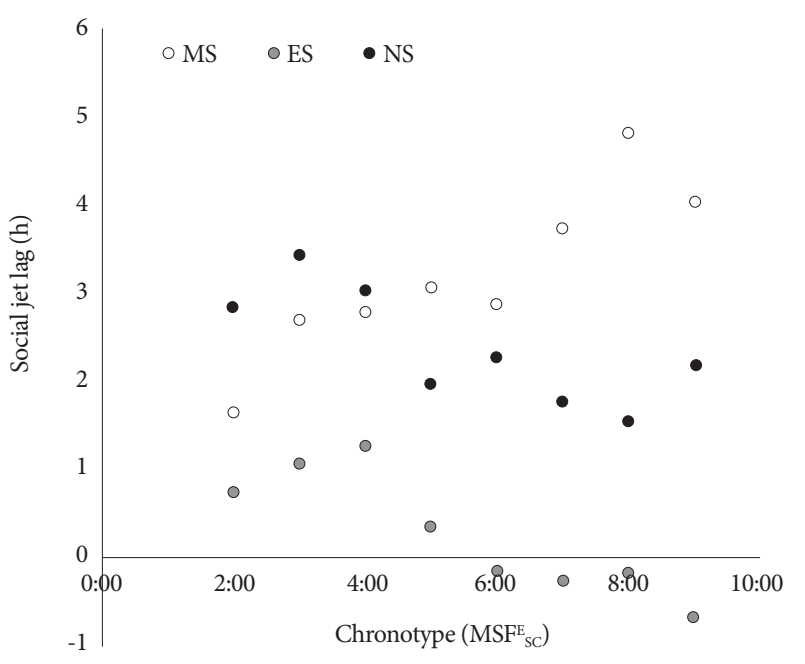

B

는 근무로 인해 자신의 일주기유형과 일치하지 않은 시간에 수면을 시도해야 하므로 수면잠복기가 다른 근무 때보다 더 길었다. 반면 휴일 지표 $\left(\mathrm{MSF}^{\mathrm{D}}\right.$ 와 $\left.\mathrm{MSF}^{\mathrm{N}}\right)$ 를 보면, $\mathrm{MSF}_{\mathrm{SC}}^{\mathrm{E}}$ 보다 지나치게 빠르거나 느린 $\mathrm{MSW}^{\mathrm{D}}$ 와 $\mathrm{MSW}^{\mathrm{N}}$ 에 비해 $\mathrm{MSF}_{\mathrm{SC}}^{\mathrm{E}}$ 와 비슷한 시간대로 수렴하는 경향을 보이는 것도, 근거가 된 다. Juda 등이 시행한 3교대 근무자를 대상으로 한 연구에서도 주간근무 동안 $\mathrm{MSF}_{\mathrm{SC}}^{\mathrm{E}}$ 가 늦을수록, 야간근무 동안 $\mathrm{MSF}_{\mathrm{SC}}^{\mathrm{E}}$ 가 빠를수록 근무일과 휴일 간 사회적 시차가 큰 것으로 보 고하여 본 연구와 유사한 결과를 보였다. ${ }^{7}$ 따라서, $\mathrm{MCTQ}^{\text {shift }}$ 로 교대근무자의 일주기유형과 교대 근무시간별 수면-각성 양상을 파악한 후 실제 근무배치를 한다면, 교대근무로 인한 수면장애를 줄일 수 있을 것으로 추정한다. 일례로 독일에서 일주기유형이 늦은 사람은 주간근무를 제한하고, 빠른 사람 은 야간근무를 제한했더니, 근로자의 수면이 훨씬 개선되었 다고 한다. ${ }^{20}$ 상근자에서 근무일과 휴일 간 사회적 시차와 건 강에 대한 보고들이 많아지고 있는데, 이는 수면과 신체적/ 정신적 건강 및 업무능력에 부정적인 영향을 미친다. ${ }^{22-24}$ 교 대근무자에서도 사회적 시차가 수면과 건강에 영향을 미친 다. ${ }^{25}$ 본 결과는 이를 극복하기 위한 다양한 연구가 수행되어 야 함을 촉구하는 근거자료가 될 것으로 추정한다.

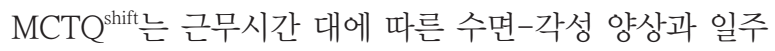
기유형을 평가하지만, 수면 중 깨어 있는 시간인 wakefulness after sleep onset(WASO)을 조사하지 않는다. 따라서, 잠이 든 시간과 깬 시간으로 수면기간은 추정하지만, 실제의 수면시간과 수면효율(sleep efficiency)을 평가할 수 없는 제 한점이 있다. 그럼에도 불구하고 본 연구대상인 교대근무 간 호사에서 주간근무 동안 수면기간이 6시간 미만인 것을 보 면, $\mathrm{WASO}$ 를 감안하여 실제 수면시간은 6시간보다 더 적을 
것으로 추정한다. 일주기유형 외에도 교대근무자의 수면시 간이나 수면효율을 평가하기 위한 객관적 검사도구(예: actigraphy)를 동반한 추가 연구가 필요하다.

본 연구의 제한점은 객관적 평가도구 없이 설문지만으로 일주기유형을 측정하여 국내 교대근무자를 대상으로 한 $\mathrm{K}-$ $\mathrm{MCTQ}^{\text {shift }}$ 도구의 준거 타당도를 조사하지 못한 것이다. 하 지만, 교대근무자의 일주기유형을 조사한 국내 최초의 연구 로서 의의가 있으며, 추후 actigraphy 등을 동시에 시행한 연 구로 확인해야 할 것이다. 또한 교대근무 형태에 따라 수면각성 양상과 일주기유형이 다를 수 있으므로, 대상군을 다양 화한 반복연구도 필요하다.

결론적으로, 한국어판 교대근무자용 뮌헨 일주기유형 설 문지 $\left(\mathrm{K}-\mathrm{MCTQ}^{\text {shift }}\right)$ 는 순환근무를 하는 교대근무자들의 근 무조에 따른 수면-각성 양상과 이에 따른 수면문제를 실제 적으로 보여주는 도구임이 확인되었다. 교대근무자의 일주 기유형 평가는 $\mathrm{MEQ}$ 도구보다 $\mathrm{K}-\mathrm{MCTQ}^{\text {shift }}$ 가 더 적절하다. 특히 근무일과 휴일 간 수면시간의 차이를 보정한 교정된 중간시간인 $\mathrm{MSF}_{\mathrm{SC}}^{\mathrm{E}}$ 를 교대근무자의 일주기유형 평가지표 로 설정하기를 제안한다. 마지막으로, 저자들은 $\mathrm{K}-\mathrm{MCTQ} \mathrm{Q}^{\text {shift }}$ 는 교대근무자의 수면을 개선하기 위한 중재연구의 평가도 구로도 적합할 것으로 판단한다.

\section{Acknowledgments}

This research was supported by Basic Science Research Program through the National Research Foundation of Korea funded by the Ministry of Science, ICT \& Future Planning, Republic of Korea (No. 2014 R1A1A3049510) and by Samsung Biomedical Research Institute grant (\#SMO1162071).

\section{REFERENCES}

1. American Academy of Sleep Medicine. The international classification of sleep disorders: diagnostic and coding manual. 2nd ed. Westchester: American Academy of Sleep Medicine, 2005.

2. Schernhammer ES, Laden F, Speizer FE, et al. Night-shift work and risk of colorectal cancer in the nurses' health study. J Natl Cancer Inst 2003;95:825-828.

3. Wolk R, Somers VK. Sleep and the metabolic syndrome. Exp Physiol 2007;92:67-78.

4. Horne JA, Ostberg O. A self-assessment questionnaire to determine morningness-eveningness in human circadian rhythms. Int J Chronobiol 1976;4:97-110.

5. Taillard J, Philip P, Bioulac B. Morningness/eveningness and the need for sleep. J Sleep Res 1999;8:291-295.

6. Ong JC, Huang JS, Kuo TF, Manber R. Characteristics of insomniacs with self-reported morning and evening chronotypes. J Clin Sleep Med 2007;3:289-294.

7. Juda M, Vetter C, Roenneberg T. Chronotype modulates sleep duration, sleep quality, and social jet lag in shift-workers. J Biol Rhythms 2013;28:141-151.

8. Pandi-Perumal SR, Smits M, Spence W, et al. Dim light melatonin onset (DLMO): a tool for the analysis of circadian phase in human sleep and chronobiological disorders. Prog Neuropsychopharmacol Biol Psychiatry 2007;31:1-11.

9. Roenneberg T, Kuehnle T, Juda M, et al. Epidemiology of the human circadian clock. Sleep Med Rev 2007;11:429-438.

10. Kitamura S, Hida A, Aritake S, et al. Validity of the Japanese version of the Munich ChronoType Questionnaire. Chronobiol Int 2014;31:845850 .

11. Zavada A, Gordijn MC, Beersma DG, Daan S, Roenneberg T. Comparison of the Munich Chronotype Questionnaire with the HorneOstberg's Morningness-Eveningness Score. Chronobiol Int 2005;22: 267-278.

12. Juda M, Vetter C, Roenneberg T. The Munich ChronoType Questionnaire for shift-workers (MCTQShift). J Biol Rhythms 2013;28:130-140.

13. Roenneberg T, Wirz-Justice A, Merrow M. Life between clocks: daily temporal patterns of human chronotypes. J Biol Rhythms 2003;18:8090.

14. Reinke L, Özbay Y, Dieperink W, Tulleken JE. The effect of chronotype on sleepiness, fatigue, and psychomotor vigilance of ICU nurses during the night shift. Intensive Care Med 2015;41:657-666.

15. Park YM, Seo YJ, Song K. The Morningness-Eveningness Questionnaire in Korean version and its relations with sleep-wake habits. J Ergon Soc Korea 1996;15:37-49.

16. World Health Organization. Process of translation and adaptation of instruments. [cited 2015 Jun 20]. Available from URL: http://www. who.int/substance_abuse/research_tools/translation/en/.

17. Roenneberg T. What is chronotype? Sleep Biol Rhythms 2012;10:75-76.

18. Roenneberg T, Kantermann T, Juda M, Vetter C, Allebrandt KV. Light and the human circadian clock. Handb Exp Pharmacol 2013;(217):311331.

19. Roenneberg T, Kuehnle T, Pramstaller PP, et al. A marker for the end of adolescence. Curr Biol 2004;14:R1038-R1039.

20. Vetter C, Fischer D, Matera JL, Roenneberg T. Aligning work and circadian time in shift workers improves sleep and reduces circadian disruption. Curr Biol 2015;25:907-911.

21. Gumenyuk V, Roth T, Drake CL. Circadian phase, sleepiness, and light exposure assessment in night workers with and without shift work disorder. Chronobiol Int 2012;29:928-936.

22. Rutters F, Lemmens SG, Adam TC, et al. Is social jetlag associated with an adverse endocrine, behavioral, and cardiovascular risk profile? J Biol Rhythms 2014;29:377-383.

23. Parsons MJ, Moffitt TE, Gregory AM, et al. Social jetlag, obesity and metabolic disorder: investigation in a cohort study. Int J Obes (Lond) 2015;39:842-848.

24. Pritchett D, Wulff K, Oliver PL, et al. Evaluating the links between schizophrenia and sleep and circadian rhythm disruption. J Neural Transm (Vienna) 2012;119:1061-1075.

25. Kantermann T, Duboutay F, Haubruge D, Kerkhofs M, SchmidtTrucksäss A, Skene DJ. Atherosclerotic risk and social jetlag in rotating shift-workers: first evidence from a pilot study. Work 2013;46:273-282. 


\section{- Appendix-}

\section{$\mathrm{MCTQ}$ 교대 근무자 설문지}

질문은 근무일과 휴일의 수면과 깨어있을 때의 행동에 대한 내용입니다. 현재 당신의 근무 시간을 고려해 답해주십시오. 꼭 모든 내용들이 채워져야 하는 것은 아닙니다. 그리고 현재 근무 일정에 맞게 답해주십시오(예를 들어, 지난 4주). 답이 어 려워 보여도 모든 질문에 답을 하려고 노력해 주십시오. 자료 분석에 도움이 되도록 시간을 명확히 적어 주십시오.
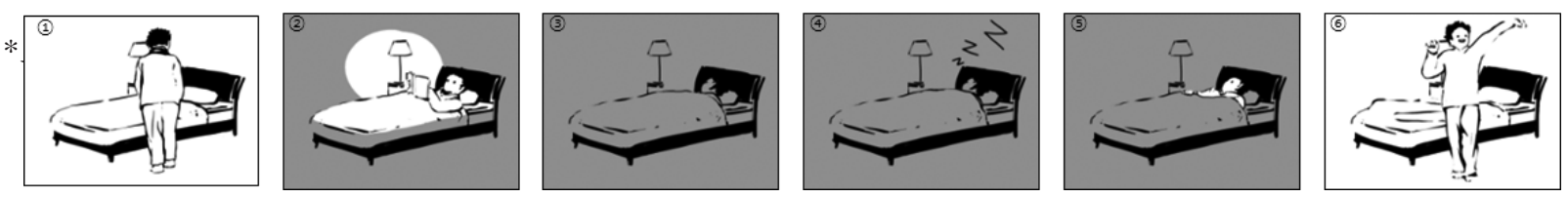

*평소 주간근무 시간: (근무 시작) 오전 시 분 (근무 끝) 오후 시 분

\section{이틀 연속 주간근무 시 중간수면}

\begin{tabular}{|l|l|l|}
\hline 주간근무 D & 수 면 & 주간근무 D \\
\hline
\end{tabular}

1. (그림 (1) 나는 잠자리에 ( $\square$ 오전 / $\square$ 오후) —시 느분에 들어간다.

(예: 새벽 1 시-오전 1 시 0 분, 자정 12 시-오전 12 시 0 분)

2. (그림 (2), (3)) 잠자리에 들어갔지만 자기 전에 다른 일(예: 핸드폰, 책 읽기 등)을 한다면, 실제 잠을 청하려고 불을 끄거나 눈을 감은 시간은 ( $\square$ 오전 / $\square$ 오후) 시 분이다.

3. (그림 (4)) 불을 끄고 잠을 청한 후 분이 지나야 잠이 든다.

4. (그림 (5) 나는 ( $\square$ 오전 / $\square$ 오후) 시 분에 잠에서 깬다. $\square$ 알람 사용 $\square$ 알람 미사용

5. (그림 (6)) 나는 잠을 깬 후, 분 뒤 침대에서 나온다.

6. 나는 낮잠을 잔다. $\square$ 예 $\square$ 아니오

6-1. 만약 ‘예’라면 나는 ( $\square$ 오전 / $\square$ 오후) 시 분부터

( $\square$ 오전 / $\square$ 오후) 시 분까지 낮잠을 잔다.

7. 자는 시간을 자유롭게 선택하지 못하는 이유가 있다. $\square$ 예 $\square$ 아니오

7-1. 만약 “예”라면: $\square$ 아이들 / 애완동물 $\square$ 취미 $\square$ 기타 예를 들면, 


\section{주간근무 이후 이틀간의 휴일 시 수면}

\begin{tabular}{|l|l|l|l|}
\hline 주간근무 D & 휴 일 & 수 면 & 휴 일 \\
\hline
\end{tabular}

1. (그림 (1) 나는 잠자리에 ( $\square$ 오전 / $\square$ 오후) 시 분에 들어간다.

(예: 새벽 1시-오전 1시 0분, 자정 12시-오전 12시 0분)

2. (그림 (2), (3)) 잠자리에 들어갔지만 자기 전에 다른 일(예: 핸드폰, 책 읽기 등)을 한다면, 실제 잠을 청하려고 불을 끄거나 눈을 감은 시간은 ( $\square$ 오전 / $\square$ 오후) 분이다.

3. (그림 (4)) 불을 끄고 잠을 청한 후 분이 지나야 잠이 든다.

4. (그림 (5) 나는 ( $\square$ 오전 / $\square$ 오후) 시 분에 잠에서 깬다. $\square$ 알람 사용 $\square$ 알람 미사용

5. (그림 (6)) 나는 잠을 깬 후, 분 뒤 침대에서 나온다.

6. 나는 낮잠을 잔다. $\square$ 예 $\square$ 아니오

6-1. 만약 '예'라면 나는 ( $\square$ 오전 / $\square$ 오후) 시 분부터

( $\square$ 오전 / $\square$ 오후) 시 분까지 낮잠을 잔다.

7. 자는 시간을 자유롭게 선택하지 못하는 이유가 있다. $\square$ 예 $\square$ 아니오

7-1. 만약 “예”라면: $\square$ 아이들 / 애완동물 $\square$ 취미 $\square$ 기타 예를 들면, 
*평소 오후근무 시간: (근무 시작) 오전 시 분 (근무 끝) 오후 시 분

\section{이틀 연속 오후근무 시 수면}

\begin{tabular}{|l|l|l|}
\hline 오후근무 $\mathrm{E}$ & 수 면 & 오후근무 $\mathrm{E}$ \\
\hline
\end{tabular}

1. (그림 (1)) 나는 잠자리에 ( $\square$ 오전 / $\square$ 오후) 시 분에 들어간다. (예: 자정 12 시-오전 12 시 0 분)

2. (그림 (2), (3)) 잠자리에 들어갔지만 자기 전에 다른 일(예: 핸드폰, 책 읽기 등)을 한다면, 실제 잠을 청하려고 불을 끄거나 눈을 감은 시간은 ( $\square$ 오전 / $\square$ 오후) 시 분이다.

3. (그림 (4)) 잠을 청한 후 분이 지나야 잠이 든다.

4. (그림 (5) 나는 ( $\square$ 오전 / $\square$ 오후) __시_분에 잠에서 깬다. $\square$ 알람 사용 $\square$ 알람 미사용

5. (그림 (6)) 나는 잠을 깬 후, 분 뒤 침대에서 나온다.

6. 나는 낮잠을 잔다. $\square$ 예 $\square$ 아니오

6-1. 만약 ‘예’라면 나는 ( $\square$ 오전 / $\square$ 오후) 시 분부터

( $\square$ 오전 / $\square$ 오후) 시 분까지 낮잠을 잔다.

7. 자는 시간을 자유롭게 선택하지 못하는 이유가 있다. $\square$ 예 $\square$ 아니오

7-1. 만약 “예”라면: $\square$ 아이들 / 애완동물 $\square$ 취미 $\square$ 기타 예를 들면,

\section{오후근무 이후 이틀간의 휴일 시 수면}

\begin{tabular}{|l|l|l|l|}
\hline 오후근무 $\mathrm{E}$ & 휴 일 & 수 면 & 휴 일 \\
\hline
\end{tabular}

1. (그림 (1) 나는 잠자리에 ( $\square$ 오전 / $\square$ 오후) _ 시 _ 분에 들어간다. (예: 자정 12 시-오전 12시 0분)

2. (그림 (2), (3)) 잠자리에 들어갔지만 자기 전에 다른 일(예: 핸드폰, 책 읽기 등)을 한다면, 실제 잠을 청하려고 불을 끄거나 눈을 감은 시간은 ( $\square$ 오전 / $\square$ 오후) 시 분이다.

3. (그림 (4)) 잠을 청한 후 분이 지나야 잠이 든다.

4. (그림 (5) 나는 ( $\square$ 오전 / $\square$ 오후) —_시 — 분에 잠에서 깬다. $\square$ 알람사용 $\square$ 알람 미사용

5. (그림 (6)) 나는 잠을 깬 후, 분 뒤 침대에서 나온다.

6. 나는 낮잠을 잔다. $\square$ 예 $\square$ 아니오

6-1. 만약 ‘예’라면 나는 ( $\square$ 오전 / $\square$ 오후) 시 분부터

( $\square$ 오전 / $\square$ 오후) 시 분까지 낮잠을 잔다.

7. 자는 시간을 자유롭게 선택하지 못하는 이유가 있다. $\square$ 예 $\square$ 아니오

7-1. 만약 “예”라면: $\square$ 아이들 / 애완동물 $\square$ 취미 $\square$ 기타 예를 들면, 
*평소 야간근무 시간: (근무 시작) 오전 시 분 (근무 끝) 오후 시 분

\section{이틀 연속 야간근무 시 수면}

\begin{tabular}{|l|l|l|}
\hline 야간근무 $\mathrm{N}$ & 수 면 & 야간근무 $\mathrm{N}$ \\
\hline
\end{tabular}

1. (그림 (1) 나는 잠자리에 ( $\square$ 오전 / $\square$ 오후) 시 분에 들어간다.

(예: 정오 12 시-오후 12 시 0 분)

2. (그림 (2), (3)) 잠자리에 들어갔지만 자기 전에 다른 일(예: 핸드폰, 책 읽기 등)을 한다면, 실제 잠을 청하려고 불을 끄거나 눈을 감은 시간은 ( $\square$ 오전 / $\square$ 오후) 시 분이다.

3. (그림 (4)) 잠을 청한 후 분이 지나야 잠이 든다.

4. (그림 (5) 나는 ( $\square$ 오전 / $\square$ 오후) —_시_분에 잠에서 깬다. $\square$ 알람 사용 $\square$ 알람 미사용

5. (그림 (6)) 나는 잠을 깬 후, 분 뒤 침대에서 나온다.

6. 나는 낮잠을 잔다. $\square$ 예 $\square$ 아니오

6-1. 만약 '예'라면 나는 ( $\square$ 오전 / $\square$ 오후) 시 분부터

( $\square$ 오전 / $\square$ 오후) 시 분까지 낮잠을 잔다.

7. 자는 시간을 자유롭게 선택하지 못하는 이유가 있다. $\square$ 예 $\square$ 아니오

7-1. 만약 “예”라면: $\square$ 아이들 / 애완동물 $\square$ 취미 $\square$ 기타 예를 들면,

\section{야간근무 후 이틀간 휴일 시 수면}

\begin{tabular}{|l|l|l|l|}
\hline 야간근무 $\mathrm{N}$ & 휴 일 & 수 면 & 휴 일 \\
\hline
\end{tabular}

1. (그림 (1) 나는 잠자리에 ( $\square$ 오전 / $\square$ 오후) _— 시 —— 분에 들어간다. (예: 정오 12시-오후 12시 0분)

2. (그림 (2), (3)) 잠자리에 들어갔지만 깨어서 다른 일(예: 핸드폰, 책 읽기 등)을 한다면, 실제 잠을 청하려고 불을 끄거나 눈을 감은 시간은 ( $\square$ 오전 / $\square$ 오후) 시 _ 분이다.

3. (그림 (4)) 잠을 청한 후 분이 지나야 잠이 든다.

4. (그림 (5)) 나는 ( $\square$ 오전 / $\square$ 오후)—_시_분에 잠에서 깬다. $\square$ 알람 사용 $\square$ 알람 미사용

5. (그림 (6)) 나는 잠을 깬 후, 분 뒤 침대에서 나온다.

6. 나는 낮잠을 잔다. $\square$ 예 $\square$ 아니오 6-1. 만약 ‘예’라면 나는 ( $\square$ 오전 / $\square$ 오후) 시 분부터

( $\square$ 오전 / $\square$ 오후) 시 분까지 낮잠을 잔다.

7. 야간근무 이후 휴일 시, 자는 시간을 자유롭게 선택하지 못하는 이유가 있다. $\square$ 예 $\square$ 아니오 7-1. 만약 “예”라면: $\square$ 아이들 / 애완동물 $\square$ 취미 $\square$ 기타 예를 들면, 